\title{
Body Mass Index and Height Growth Curves are Influenced by Sexual Maturation Status in Brazil: Cross-Sectional Study
}

\begin{abstract}
Fernando Adami1, 3, 4, 6, Jucemar Benedet ${ }^{2}$, Adair da Silva Lopes ${ }^{2}$, Maria Gabriela Matias de Pinho ${ }^{5}$ Francisco Winter dos Santos Figueiredo 4,6 Laércio da Silva Paiva 4, 6 , Luiz Carlos de Abreu 4,7,

Francisco de Assis Guedes de Vasconcelos ${ }^{5}$
\end{abstract}

\section{Abstract}

Background: To describe and analyze growth curves of body mass index (BMI) and height according to sexual maturation status in children and adolescents aged 8-14 years old in the city of Florianópolis, Santa Catarina, Brazil.

Methods: Cross-sectional study conducted in 2007 with a random sample of 2,339 students from public and private elementary school. Excess weight was determined by BMI curves of the World Health Organization according to sex and age. Sexual maturation was selfassessed and classified according to Tanner stages of sexual development. Tertiles of age in each sexual maturation stage were used to classify individuals in early, normal or late sexual maturation. Growth curves of BMI and height were estimated using median values for each sex, using six degree polynomial to smooth the curve.

Results: We observed different growth curves of BMI and height according to sexual maturation status for both boys and girls. Early sexual maturation is associated with increased BMI z score to boys until 11 years of age and to girls in all groups age, and with increased height $z$ score to boys in all age groups and in girls of 9-12.5 years of age. Late sexual maturation is associated with lower values of BMI $Z$ score in boys between 10 to 12 years of age and slower evolution of BMI Z score in girls.
1 Bolsista do Conselho Nacional de Desenvolvimento Científico e Desenvolvimento Tecnológico - CNPq.

2 Departamento de Educação Física. Programa de Pós-Graduação em Educação Física - Centro de Desportos - Universidade Federal de Santa Catarina, Florianópolis - SC, Brazil.

3 Programa de Pós-Graduação em Saúde Coletiva, Universidade do Extremo Sul Catarinense. Criciúma-SC, Brazil.

4 Departamento de Saúde da Coletividade. Laboratório de Epidemiologia e Análise de dados, Laboratório de Delineamento de Estudos e Escrita Científica, Faculdade de Medicina do ABC, Santo André - SP, Brazil.

5 Departamento de Nutrição. Programa de Pós-graduação em Nutrição do Centro de Ciências da Saúde Universidade Federal de Santa Catarina - UFSC. Centro de Ciências da Saúde., Florianópolis - SC, Brazil.

6 Instituto Brasileiro de Ensino e Pesquisa - IBESPA.

7 Harvard T.H. CHAN School of Public Health. Department of Environmental Health, 665 Huntington Avenue, Boston, MA 02115.

Contact information:

\section{Fernando Adami.}

Address: Av., Príncipe de Gales, CEP 09060650, Santo André, São Paulo, Brasil.

Tel: +55 (11) 96062-0133.

” fernando.adami@fmabc.br 
Conclusion: The sexual maturation seems to affect directly the evolution of BMI and height and should be considered in the assessment of nutritional status during childhood.

\section{Keywords}

Schoolchildren; Curves;

Growth; Obesity;

Sexual Maturation.

\section{Introduction}

In recent decades, concern surrounding excessive body mass index (BMI) gain increased the use of growth curves in the analysis of the relationship among anthropometric indicators of growth, nutritional status and health of children and adolescents. [1] However, assessing nutritional status using only $\mathrm{BMI}$ and height cannot accurately identify changes in body composition in this population, as both tend to increase significantly in each sexual maturation stage. $[2,3,4]$

Although growth and sexual maturation occur simultaneously and both promote changes in shape, size and body composition, growth involves quantitative biological aspects, while sexual maturation is a biological phenomenon which takes place in puberty and is related to the maturation of sex organs and their functions. $[5,6]$

In addition, changes in body composition during puberty occur in different ways for males and females, while boys have an increase in fat-free mass, girls have an increase in fat mass. $[7,8]$ Studies have shown that children with early sexual maturation tend to be heavier, stronger and higher during adolescence compared to those with normal or late sexual maturation. $[9,10]$

It is important to note, though, that this premature gain does not seem to translate into greater height in adulthood in both females [10] and males. [11] On the other hand, there are indications that early sexual maturation increases the risk of excessive adiposity in adulthood in males [13] and leads to higher BMI in early adulthood in females. [14]

For these reasons, graphical representations of growth indicators accounting for sexual maturation stages in boys and girls become an important tool to better understand changes in body composition. Despite this fact, sexual maturation is still under explored in most studies investigating the relations of anthropometric indicators of growth, nutritional status and health.

Therefore, considering that growth curves are not described according to sexual maturation status and that sexual maturation status can change the shape of growth curves for BMI and height, the objective of the study was to describe and analyze BMI and height growth curves according to sexual maturation status in children and adolescents aged 8-14 years in the city of Florianópolis, Santa Catarina, Brazil.

\section{Methods}

Cross-sectional study conducted in the city of Florianópolis, Santa Catarina, southern Brazil, from April to October 2007. The study was planned according to guidelines of the Strengthening the Reporting of Observational Studies in Epidemiology (STROBE). [15] Sampling details can be found in other publications. [16-18] The closest relatives, carers or guardians had to consent writing children's participation in the study according with a term Informed Consent (IC). The study was approved by the Ethics Committee 83 of the Federal University of Santa Catarina ( $n^{\circ}$ 028/06).

Briefly, for sample size calculation, the following parameters were assumed: excess weight prevalence of $22.1 \%$ for children aged $7-10$ years [16] and $12.6 \%$ for those aged 11-14 years; [19] acceptable error of 3 percentage points; two-tailed test; confidence level of 95\%; design effect of 1.5; and an 
addition of $10 \%$ for losses. The sampling procedure was probabilistic, stratified by clusters and performed in two stages (school and children).

Schools were grouped in four strata, according to geographical area (center/continent or beaches) and school type (public or private). In the first stage, schools were randomly selected from each stratum. From 87 schools (33 private and 54 public), 6 private and 11 public schools were selected. In the second stage, children and adolescents were randomly selected according to age.

Anthropometric measurements were performed according to WHO guidelines [20], proposed by Lohman et al. [21]. The team responsible for data collection included 10 people previously trained in a workshop held between September 2006 and March 2007, which consisted of theoretical and practical sessions on anthropometric measurements.

We performed pilot study and standardization anthropometric measures (assessment of intra- and inter- observer errors) [22] in two schools (one public and one private), which were excluded from the sampling of the study.

Excess weight was determined using growth curves of BMI for age and sex, proposed by the World Health Organization. [23] Height and BMI were analyzed by Z score values (height and BMI Z score) according to age and sex. A threshold of five was adopted to classify implausible values of height and BMI Z score. [23]

Birth weight was reported by parent or primary caregiver, who was asked to check the participant's health record. Values were classified according to the World Health Organization cutoff values [20] into low (< $2.500 \mathrm{~g})$, normal ( $\geq 2.500 \mathrm{~g}-3.999 \mathrm{~g})$ and high birth weight $(\geq 4.000 \mathrm{~g})$. Maternal nutritional status was evaluated by BMI, using self-reported weight and height and classified according to the World Health Organization criteria [23] as normal weight $\left(<25 \mathrm{~kg} / \mathrm{m}^{2}\right)$ and excess weight $\left(\geq 25 \mathrm{~kg} / \mathrm{m}^{2}\right)$.

Further information (name, date of birth, school grade and type of school) was obtained in docu- ments provided by the school. The type of school refers to public or private. Information about commuting to school was collected by an illustrated questionnaire and subjects were classified as active (walking and biking) or inactive (car, bus, passenger in motorcycle or bicycle).

Sexual maturation was determined based on the stages of development proposed by Tanner, comprising five stages of development of genitals (males) [25] and genitals/breasts (females). [26] Children and adolescents received instructions individually by a research team member in a private environment and were asked to perform a self-evaluation.

Tertiles of age (in decimals) for each of the five development stages were estimated for both sexes. [27] For each stage, school children were divided in early sexual maturation (below first tertile of age), late sexual maturation (second tertile or more) and normal sexual maturation or reference group (between the first and the second tertile).

$\mathrm{BMI}$ and height growth curves according to sexual maturation status -early, normal and late-were estimated using median values of age (in years) for both sexes, using 6th degree polynomial to smooth the curve.

In order to describe the study sample, prevalence of overweight, birth weight, active commuting to school, school type and maternal overweight were presented in absolute and relative frequency by sex and analyzed using Rao-Scott test.

Age, BMI and height $Z$ score did not follow a normal distribution (Shapiro-Wilk test with $p<0.05$ ) and, thus, they were presented as medians and 25th and 75th percentiles and analyzed by sex using Mann-Whitney test.

Due to the stratified probabilistic sampling, estimates accounted for sampling weights and strata using svy command. The significance level was 95\%. The statistical program used was Stata (Statistical Software for Professionals, Texas) version $11.0^{\circledR}$. 


\section{Results}

Of the 2,898 potentially eligible participants, 289 aged seven, 197 with no data on sexual maturation and 73 with inconsistent data on sexual maturation were excluded. 2,339 participants aged 8 to 14 years (52.3\% female) were included, resulting in a response rate of $82.8 \%$. There were no statistically significant differences in the prevalence of overweight, BMI Z score values, height Z score values and other variables between excluded individuals and study participants.

Male students had higher BMI Z score ( $p<0.001)$, height $Z$ score $(p=0.002)$, prevalence of overweight $(p<0.001)$ and of high birth weight $(p<0.001)$. There were no differences in other variables (Table 1).

By analyzing BMI growth curves according to sexual maturation status in boys (Figure $1 \mathrm{~A}$ ) and girls (Figure 1B), it is observed: i) lower values of BMI Z score for boys with late sexual maturation from 10 to 12.5 years of age (Figure $1 \mathrm{~A}$ ); ii) trend of higher BMI Z score values in girls with early sexual maturation from all age groups (Figure 1B); iii) slower evolution of BMI z score in girls with late sexual maturation (Figure 1B).

Comparing the evolution of height $Z$ score curves according to sexual maturation stages (early, normal and late), it is noticed: i) greater height-for-age in early maturing boys from all age groups and lower height for those with late sexual maturation (Figure $2 A)$; ii) greater height in early maturing girls from nine to twelve years of age and; iii) lower height for late maturing girls from 9 to 14 years old (Figure 2B).

\section{Discussion}

Analysing BMI and height growth curves of children and adolescents aged 8-14 years according to sexual maturation resulted in three main findings: i) BMI and height growth curves differ according to sexual maturation status for both boys and girls; ii) Early sexual maturation is associated with increased
Table 1. Distribution of female victims of rape as a category of gestational age and sociodemographic characteristics, São Paulo, 1994-2013.

\begin{tabular}{|c|c|c|c|}
\hline \multirow{2}{*}{$\begin{array}{c}\text { Study } \\
\text { variables }\end{array}$} & Males & Females & \multirow{2}{*}{$p^{\S}$} \\
\hline & $(47.7 \%)$ & $(52.3 \%)$ & \\
\hline \multicolumn{4}{|c|}{ Median (p25; p75)* } \\
\hline Age (years) & $11(10 ; 13)$ & $12(10 ; 13)$ & 0.530 \\
\hline BMI Z score & $0.51(-0.22 ; 1.42)$ & $0.21(-0.41 ; 0.96)$ & $<0.001$ \\
\hline $\begin{array}{l}\text { Height Z } \\
\text { score }\end{array}$ & $0.25(-0.41 ; 0.99)$ & $0.11(-0.52 ; 0.79)$ & 0.002 \\
\hline
\end{tabular}

\section{$\%$}

\begin{tabular}{l|l|l|l|}
\hline $\begin{array}{l}\text { Excess } \\
\text { weight }\end{array}$ & 34.4 & 24.0 & $<0.001$ \\
\hline $\begin{array}{l}\text { Sexual maturations stage } \\
\text { Early }\end{array}$ & 33.1 & 32.5 & 0.940 \\
\hline Late & 32.2 & 32.7 & \\
\hline $\begin{array}{l}\text { Maternal } \\
\text { excess } \\
\text { weight }\end{array}$ & 31.0 & 33.4 & 0.310 \\
\hline
\end{tabular}

Birth weight (grams)

\begin{tabular}{l|c|c|c}
$<2,500$ & 5.8 & 8.3 & $<0.001$ \\
\hline 4,000 & 14.4 & 8.1 &
\end{tabular}

\begin{tabular}{l|l|l|l|} 
Active & & & \\
commuting & 43.6 & 45.0 & 0.560 \\
to school & & &
\end{tabular}

School type

\begin{tabular}{|l|l|l|l|}
\hline Public & 65.4 & 65.5 & 0.970 \\
\hline Private & 34.6 & 34.5 & \\
\hline
\end{tabular}

* p25 and p75: percentiles 25 and 75, respectively;

$\S$ Mann-Whitney test (quantitative variables) and Rao-Scott test (qualitative variables).

BMI z score to boys until 11 years of age and to girls in all groups age, well as with increased height to boys in all age groups and in girls of 9-12.5 years of age; iii ) Late sexual maturation status is related to lower BMI Z score in boys from 10 to 12 years old and slower evolution of BMI Z score in girls.

This study has some strengths that differentiate those found in the literature as sample size and homogeneity of study population, such as low sample 
Figure 1: BMI Z score growth curves according to sexual maturation classification in male $(A)$ and female (B) children and adolescents. Florianópolis, southern Brazil, 2007.
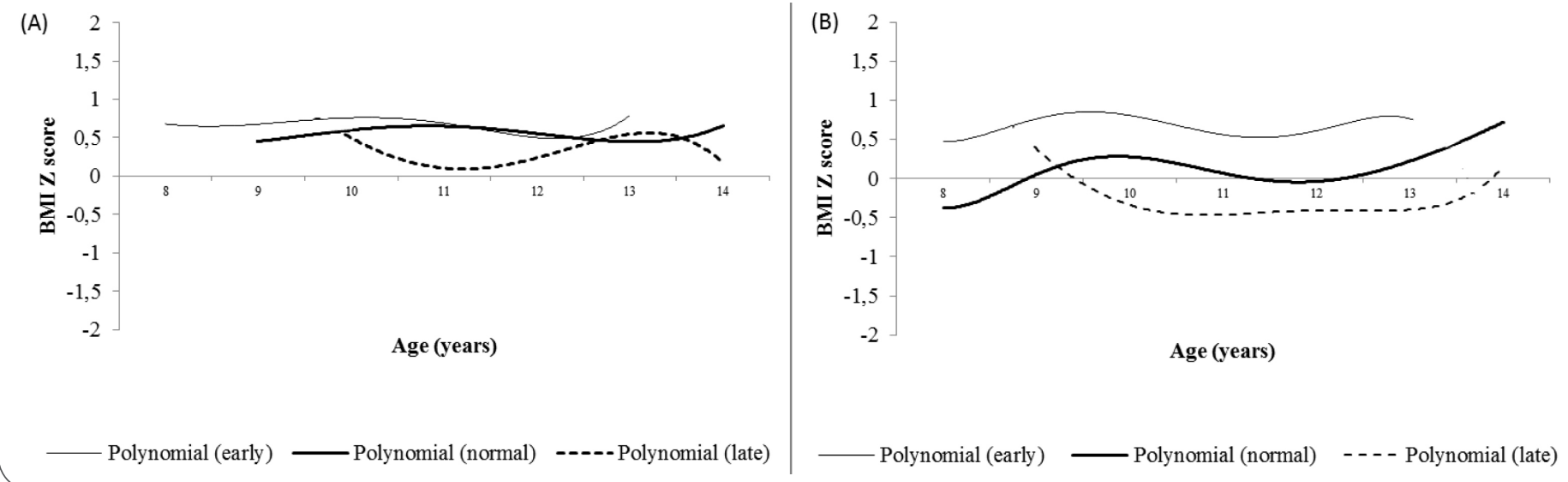

Figure 2: Height Z score growth curves according to sexual maturation classification in male (A) and female (B) children and adolescents. Florianópolis, southern Brazil, 2007.
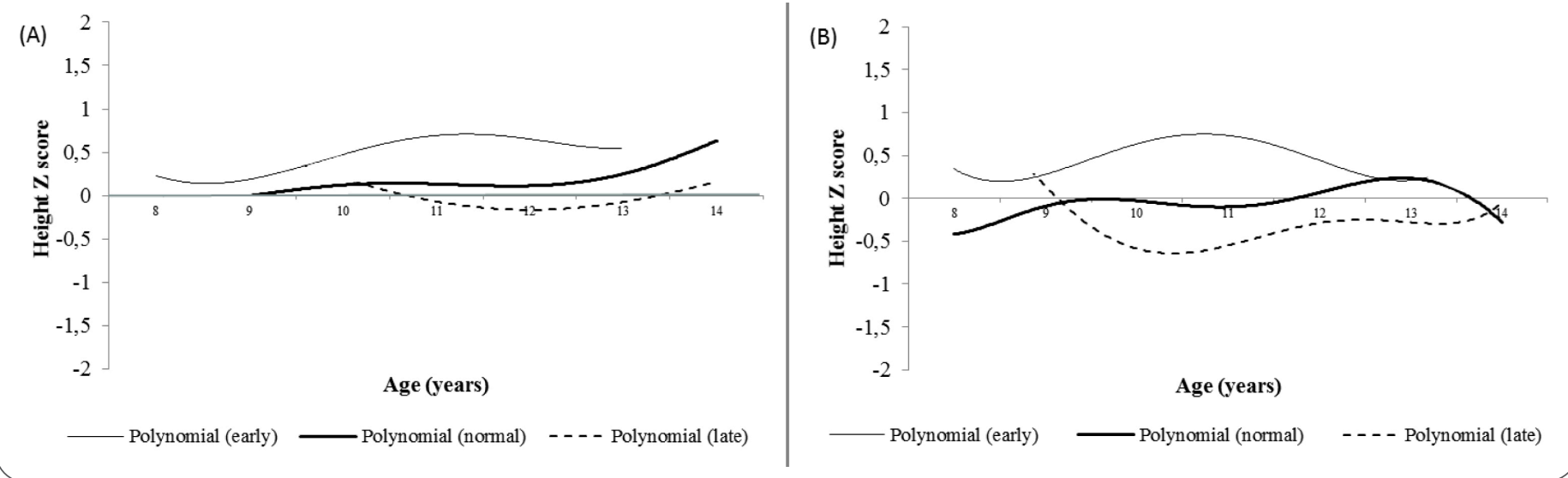

loss and rigorous sampling procedures, collection and analysis of data, reducing the possibility of selection and measurement bias, which combined with the school-based characteristic, reinforce the study's internal and external validity.

A limitation of the study may be related to the use of self-assessed sexual maturation. However, this procedure on field research has been validated in studies with Brazilian adolescents, [28, 29] which show a good correlation $(r=0.80)$ between the measurements from self-evaluation and from experienced personnel.

In general, children and adolescents with early sexual maturation have higher values of BMI Z scores and greater height-for-age (height $Z$ score). These findings reinforce the trend that BMI is strongly associated with height in cases of early puberty in both sexes, which did not occur at late puberty. [30] In this context, Silva et al. [31] and Soares et al. [32] emphasize that the observation of the sex maturation stage enables the acquisition of more concrete data on the actual changes occurring in population groups at any stage of development.

Concerning the biological aspect of BMI relation to sexual maturation, it is evident that the measurement of body weight and its main components (fat mass and lean mass), especially during puberty, have different rhythms and proportions between the sexes and among ethnicities. In addition, concerning environmental issues, community-specific 
references may reflect more clearly nutritional characteristics and growth trend of each population.

Studies evaluating BMI patterns in relation to sexual maturation are scarce and difficult to compare given the methodological specificities. Díazet al. [3] evaluated children and adolescents from 7 to 17 years of age, of both sexes, and concluded that $\mathrm{BMI}$ increased significantly in every sexual maturation stage ( 0.5 to $\left.1.3 \mathrm{~kg} / \mathrm{m}^{2}\right)$.

In our study, the influence of sexual maturation stages on BMI was less evident in males compared to females. In fact, there are studies indicating that sexual maturation status was either not significantly related to increased BMI [33] or weakly correlated with BMI in males. [34]

However, our results suggest that males with early sexual maturation presented an early increase in BMI, contrasting with the fact that males with late sexual maturation only achieved BMI values similar to the other groups around the age of 13 years.

Van Lenthe et al. [35] also observed that adiposity decreased in the presence of early sexual maturation at ages 13, 14 and 15 years, while it increased in late sexual maturation among boys. As noted in this study, it seems that, regardless of the anticipation of pubertal events, BMI values tend to adjust in late adolescence, due to changes in fat or lean mass.

In several studies, [27, 36-38] female children and adolescent with early maturation had higher BMI values, as in this study.

More specifically, our findings corroborate the conclusions of Biro et al., [14] which showed that children and adolescents ( 9 and 19 years) with early sexual maturation showed greater median BMI along the entire follow-up period (10 years), compared with normal and late maturing individuals.

Although an increased BMI may cause early maturation, $[2,39]$ it is important to note that sexual maturation and increased BMI are phenomena that occur in parallel, it is difficult to establish whether increased $\mathrm{BMI}$ is a consequence or an early determinant of precocious puberty.
Undoubtedly, this remains a matter of debate, [40] since it is difficult to separate the effects of early obesity from the effects of early maturation. [41] Regardless of these trends, our findings indicate that the evolution of BMI in children with normal or late maturation is slower, which could be protective against overweight in adulthood. In this sense, longitudinal studies can provide more conclusive results on this topic.

With regard to the association between sexual maturation stage and height, the results of this study confirmed the trend towards greater height for age during the pubertal period among early maturing individuals of both sexes.

Several studies found similar trends to those described in this study. In a cross-sectional study, Adami and Vasconcelos [27] showed that children and adolescents from both sexes (10 to 14 years old) with early sexual maturation have greater height for age when compared to those who do not have early sexual maturation. Besides, Lewitt et al. [30] studied the relationship among sexual maturation stages, BMI and height of boys and girls aged 8 years or more and concluded that BMI is strongly correlated with height in cases of early puberty in both sexes.

Women with early puberty have a rapid physical growth in early life, but shorter stature in adult life. [11] According to a systematic review by OnlandMoret et al. [41], girls with early sexual maturation have lower adult height compared with normal or late maturing girls.

Biologically, the early onset of puberty can lead to an acceleration of skeletal maturation and lower pre-pubertal growth due to the closure of epiphyseal cartilage of long bones. [43] Indeed, according Biro et al., [14] early maturing girls were shorter in early adulthood, although they had higher growth peak initially and greater increase in weight after menarche. Regarding the higher initial growth peak, the findings are similar to those identified in this study. 
Thus, it is likely that subjects who have early sexual maturation have greater height for age only during puberty years. This is explained as the simultaneous occurrence of early development of secondary sexual characteristics and the growth curve is common.

On the other hand, individuals with late sexual maturation can have greater stature in adulthood. A study evaluating the relationship between the onset of puberty and height at 18 years of age found that girls with late onset of breast development and of menarche were higher in adult life: each year increase in age of these markers were associated with $0.46 \mathrm{~cm}$ and $0.59 \mathrm{~cm}$ increase in height at 18 years old, respectively. [44]

Apparently, even though individuals with early sexual maturation may be higher, a smaller gain in height during adolescence contrasts the beneficial effect of greater height during the early years of puberty in early maturing. [27]

This is justified by the tendency that early sexual maturation is associated with lower height gains during adolescence. [45] However, longitudinal studies, including genetic components and hormonal factors, are needed to better understand the biological mechanisms behind these associations. [46]

Research should be implemented to give visibility to situations like these, however, while in Brazil the scientific production has been increasing significantly increase with the proper training of health professionals who work with research in project management $[47,48]$.

Our results indicate that sexual maturation status seems to affect directly the evolution of BMI and height, increasing BMI and height in early sexual maturation, reducing BMI of boys and causing slower evolution of BMI in late sexual maturation.

The graphical representation of these indicators facilitates the interpretation of data and promotes the understanding of $\mathrm{BMI}$ and height patterns during puberty. The trend of higher BMI Z scores and a greater height for age in children and adolescents with early sexual maturation should be seen as an important factor for nutritional status. Therefore, it is important to consider the sexual maturation status in the assessment of nutritional status during childhood.

\section{Conflicts of interests}

None of the authors have conflicts of interest to declare.

\section{Funding}

Conselho Nacional de Desenvolvimento Científico e Tecnológico (CNPq) (number 158885/2014-7).

\section{Financial disclosures}

None of the authors have financial disclosures.

\section{Authors' contribution}

FA and JB participated in the study design, statistical analysis, writing and approved the final version of the manuscript.

ASL, FAGV, LCA and MGMP contributed to writing, reviewing the paper and approved the final version of the manuscript.

FWSF and LSP contributed to writing, statistical analysis, reviewing the paper and approved the final version of the manuscript.

\section{References}

1. Grummer-Strawn LM, Reinold C, Krebs NF. Use of World Health Organization and CDC growth charts for children aged 0-59 months in the United States. MMWR Recomm Rep. 2010;59 (Rr-9): 1-15. Epub 2010/09/11. PubMed PMID: 20829749.

2. Castilho SD, Saito MI, Barros Filho AdA. Crescimento pós-menarca em uma coorte de meninas brasileiras. Arquivos Brasileiros de Endocrinologia \& Metabologia. 2005; 49: 971-7.

3. Díaz E, Burrows R, Muzzo S, Galgani J, Rodriguez R. Evaluación nutricional de adolescentes mediante índice de masa corporal para etapa puberal. Rev ChilPediatr [Internet]. 1996; 67: [153-8 pp.].

4. Benedet, J. Lopes, AS. Adami, F. Hinnig, PF. Vasconcelos, FAG. Association of sexual maturation with excess body weight and height in children and adolescents. BMC Pediatrics, v. 14, p. 72, 2014. 
5. Barbosa KBF, Franceschini SdCC, Priore SE. Influência dos estágios de maturação sexual no estado nutricional, antropometria e composição corporal de adolescentes. Revista Brasileira de Saúde Materno Infantil. 2006; 6: 375-82.

6. Rogol AD, Roemmich JN, Clark PA. Growth at puberty. J Adolesc Health. 2002; 31(6 Suppl): 192-200. Epub 2002/12/10. PubMed PMID: 12470915.

7. Loomba-Albrecht LA, Styne DM. Effect of puberty on body composition. Curr Opin Endocrinol Diabetes Obes. 2009; 16(1): 10-5. Epub 2009/01/01. PubMed PMID: 19115520.

8. Luciano, AP. Benedet, J. Abreu, LC. Valenti, VE. Almeida, FS. Vasconcelos, FAG. Adami, F. Median ages at stages of sexual maturity and excess weight in school children. Reproductive Health, v. 10, p. 56, 2013.

9. Biassio LG, Matsudo SMM, Matsudo VKRldd-c-wqqsqlp, 414.008px $t, 16.6667 p x f-s$, sans-serif $f-f$, et al. Impacto da menarca nas variáveis antropométricas e neuromotoras da aptidão física, analisado longitudinalmente. $R$ Bras Ci e Mov [Internet]. 2004; 12: [97-101 pp.].

10. Pearson DT, Naughton GA, Torode M. Predictability of physiological testing and the role of maturation in talent identification for adolescent team sports. J Sci Med Sport. 2006; 9(4): 277-87. Epub 2006/07/18. doi: 10.1016/j. jsams.2006.05.020. PubMed PMID: 16844415.

11. Brown JJ, Warne GL, 365.026px Idd-c-wqqsql, 212.495px t, $17.5 p x f-s$, serif f-f, et al. Growth in Precocious Puberty. Indian J Pediat [Internet]. 2006; 73: [81-8 pp.].

12. Philippaerts RM, Vaeyens $R$, Janssens $M$, Van Renterghem $B$, Matthys $D$, Craen $R$, et al. The relationship between peak height velocity and physical performance in youth soccer players. J Sports Sci. 2006; 24(3): 221-30. Epub 2005/12/22. doi: 10.1080/02640410500189371. PubMed PMID: 16368632.

13. Kindblom JM, Lorentzon M, Norjavaara E, Lonn L, Brandberg J, Angelhed JE, et al. Pubertal timing is an independent predictor of central adiposity in young adult males: the Gothenburg osteoporosis and obesity determinants study. Diabetes. 2006; 55(11): 3047-52. Epub 2006/10/27. doi: 10.2337/db06-0192. PubMed PMID: 17065341

14. Biro FM, McMahon RP, Striegel-Moore R, Crawford PB, Obarzanek E, Morrison JA, et al. Impact of timing of pubertal maturation on growth in black and white female adolescents: The National Heart, Lung, and Blood Institute Growth and Health Study. J Pediatr. 2001; 138(5): 636-43. Epub 2001/05/09. doi: 10.1067/mpd.2001.114476. PubMed PMID: 11343036.

15. Malta M, Cardoso LO, Bastos Fl, Magnanini MM, Silva CM. STROBE initiative: guidelines on reporting observational studies. Rev Saude Publica. 2010; 44(3): 559-65. Epub 2010/06/16. PubMed PMID: 20549022.

16. de Assis MA, Rolland-Cachera MF, Grosseman S, de Vasconcelos FA, Luna ME, Calvo MC, et al. Obesity, overweight and thinness in schoolchildren of the city of Florianopolis, Southern Brazil. Eur J Clin Nutr. 2005; 59(9): 1015-21. Epub 2005/06/23. doi: 10.1038/sj.ejcn.1602206. PubMed PMID: 15970941
17. Bernardo Cde O, Vasconcelos Fde A. Association of parents' nutritional status, and sociodemographic and dietary factors with overweight/obesity in schoolchildren 7 to 14 years old. Cad Saude Publica. 2012; 28(2): 291-304. Epub 2012/02/15. PubMed PMID: 22331155.

18. Benedet J, Assis MA, Calvo MC, Andrade DF. Overweight in adolescents: exploring potential risk factors. Rev Paul Pediatr. 2013; 31(2): 172-81. Epub 2013/07/06. PubMed PMID: 23828053.

19. Wang Y, Monteiro C, Popkin BM. Trends of obesity and underweight in older children and adolescents in the United States, Brazil, China, and Russia. Am J Clin Nutr. 2002; 75(6): 971-7. Epub 2002/05/31. PubMed PMID: 12036801.

20. Physical status: the use and interpretation of anthropometry. Geneva: World Health Organization; 1995.

21. Lohman TG RA, Martorell R. Anthropometric standardization reference manual. Illinois: Human Kinetics Books; 1988.

22. Frainer DE, Adami F, Vasconcelos Fde A, Assis MA, Calvo MC, Kerpel R. [Standardization and reliability of anthropometric measurements for population surveys]. Arch Latinoam Nutr. 2007; 57(4): 335-42. Epub 2008/06/06. PubMed PMID: 18524317.

23. de Onis M, Onyango AW, Borghi E, Siyam A, Nishida C, Siekmann J. Development of a WHO growth reference for school-aged children and adolescents. Bull World Health Organ. 2007; 85(9): 660-7. Epub 2007/11/21. PubMed PMID: 18026621; PubMed Central PMCID: PMCPmc2636412.

24. Obesity: preventing and managing the global epidemic. Report of a WHO consultation. World Health Organ Tech Rep Ser. 2000; 894: i-xii, 1-253. Epub 2001/03/10. PubMed PMID: 11234459.

25. Marshall WA, Tanner JM. Variations in the Pattern of Pubertal Changes in Boys. Arch Dis Child. 1970; 45(239): 13-23. PubMed PMID: 5440182; PubMed Central PMCID: PMCPmc2020414.

26. Marshall WA, Tanner JM. Variations in pattern of pubertal changes in girls. Arch Dis Child. 1969; 44(235): 291-303. PubMed PMID: 5785179; PubMed Central PMCID: PMCPmc2020314.

27. Adami F, Vasconcelos FdAGd. Obesidade e maturação sexual precoce em escolares de Florianópolis - SC. Revista Brasileira de Epidemiologia. 2008; 11: 549-60.

28. Matsudo SM MV. Validade da auto-avaliação da maturação sexual. Rev Bras Cienc Mov [Internet]. 1991; 5: [18-35 pp.].

29. Saito Ml. Maturação sexual: auto-avaliação do adolescente. Pediatria [Internet]. 1984; 6: [111-5 pp.].

30. Lewitt MS, Baker JS, Mooney GP, Hall K, Thomas NE. Pubertal stage and measures of adiposity in British schoolchildren. Ann Hum Biol. 2012; 39(5): 440-7. Epub 2012/08/07. doi: 10.3109/03014460.2012.704070. PubMed PMID: 22862419

31. Silva RJds, Silva Júnior AG, Oliveira ACCd. Growth in children and adolescents: a comparative study. Brazilian Journal of Kinanthropometry and Human Performance; Vol 7, No 1 (2005). 2006.

32. Soares NT. Um novo referencial antropométrico de crescimento: significados e implicações. Revista de Nutrição. 2003; 16: 93103. 
33. Kanbur NO, Derman O, Kinik E. Prevalence of obesity in adolescents and the impact of sexual maturation stage on body mass index in obese adolescents. Int J Adolesc Med Health. 2002; 14(1): 61-5. Epub 2002/12/07. PubMed PMID: 12467208.

34. Castilho SD, Cocetti M, de Azevedo Barros Filho A. Body mass index and body composition in relation to sexual maturation. J Pediatr Endocrinol Metab. 2008; 21(2): 127-33. Epub 2008/04/22. PubMed PMID: 18422025

35. van Lenthe FJ, Kemper CG, van Mechelen W. Rapid maturation in adolescence results in greater obesity in adulthood: the Amsterdam Growth and Health Study. Am J Clin Nutr. 1996; 64(1): 18-24. Epub 1996/07/01. PubMed PMID: 8669409.

36. Kilic A, Durmus MS, Unuvar E, Yildiz I, Aydin BK, Ucar A, et al. Clinical and laboratory characteristics of children referred for early puberty: preponderance in 7-8 years of age. J Clin Res Pediatr Endocrinol. 2012; 4(4): 208-12. Epub 2012/12/25. doi: 10.4274/jcrpe.736. PubMed PMID: 23261863; PubMed Central PMCID: PMCPmc3537288.

37. Ribeiro J, Santos P, Duarte J, Mota J. Association between overweight and early sexual maturation in Portuguese boys and girls. Ann Hum Biol. 2006; 33(1): 55-63. Epub 2006/02/28. doi: 10.1080/00207390500434135. PubMed PMID: 16500811.

38. Himes JH, Obarzanek E, Baranowski T, Wilson DM, Rochon J, McClanahan BS. Early sexual maturation, body composition, and obesity in African-American girls. Obes Res. 2004; 12 Suppl: 64s-72s. Epub 2004/10/19. doi: 10.1038/oby.2004.270. PubMed PMID: 15489469.

39. Wang $Y$. Is obesity associated with early sexual maturation? A comparison of the association in American boys versus girls. Pediatrics. 2002; 110(5): 903-10. Epub 2002/11/05. PubMed PMID: 12415028.

40. Adair LS. Child and adolescent obesity: epidemiology and developmental perspectives. Physiol Behav. 2008; 94(1): 8-16. Epub 2008/01/15. doi: 10.1016/j.physbeh.2007.11.016. PubMed PMID: 18191968.

41. Bratberg GH, Nilsen TI, Holmen TL, Vatten LJ. Early sexual maturation, central adiposity and subsequent overweight in late adolescence. a four-year follow-up of 1605 adolescent Norwegian boys and girls: the Young HUNT study. BMC Public Health. 2007; 7: 54. Epub 2007/04/14. doi: 10.1186/14712458-7-54. PubMed PMID: 17430580; PubMed Central PMCID: PMCPmc1855319.

42. Onland-Moret NC, Peeters PH, van Gils CH, Clavel-Chapelon F, Key $\mathrm{T}$, Tjonneland $\mathrm{A}$, et al. Age at menarche in relation to adult height: the EPIC study. Am J Epidemiol. 2005; 162(7): 623-32. Epub 2005/08/19. doi: 10.1093/aje/kwi260. PubMed PMID: 16107566

43. Tanner JM, Whitehouse RH, Marubini E, Resele LF. The adolescent growth spurt of boys and girls of the Harpenden growth study. Ann Hum Biol. 1976; 3(2): 109-26. Epub 1976/03/01. PubMed PMID: 1275435

44. Yousefi $M$, Karmaus $W$, Zhang $H$, Roberts $G$, Matthews $S$, Clayton $B$, et al. Relationships between age of puberty onset and height at age 18 years in girls and boys. World J Pediatr. 2013; 9(3): 230-8. Epub 2013/01/22. doi: 10.1007/s12519-0130399-z. PubMed PMID: 23335183.
45. He Q, Karlberg J. Bmi in childhood and its association with height gain, timing of puberty, and final height. Pediatr Res. 2001; 49(2): 244-51. Epub 2001/02/07. doi: 10.1203/00006450200102000-00019. PubMed PMID: 11158521.

46. Silventoinen K, Haukka J, Dunkel L, Tynelius P, Rasmussen F. Genetics of pubertal timing and its associations with relative weight in childhood and adult height: the Swedish Young Male Twins Study. Pediatrics. 2008; 121(4): e885-91. Epub 2008/04/03. doi: 10.1542/peds.2007-1615. PubMed PMID: 18381517.

47. Monteiro CBM, Almeida Junior AD, Wajnzstejn R. Project Management in Health and Medical Research. Journal of Human Growth and Development. 2014; 24(3): 239-242

48. Bezerra IMP, et al. Professional activity in the context of health education: a systematic review. Journal of Human Growth and Development. 24(3): 255-262. doi.org/10.7322/jhdg.88909

\section{Comment on this article:}

\section{A) $B$ in $8+\mathbf{S} P$}

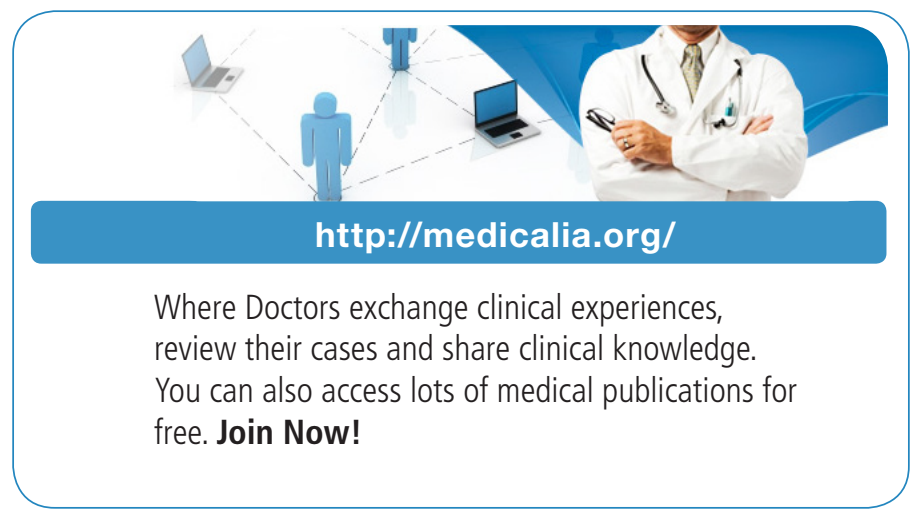

\section{Publish with iMedPub}

\section{http://www.imed.pub}

International Archives of Medicine is an open access journal publishing articles encompassing all aspects of medical science and clinical practice. IAM is considered a megajournal with independent sections on all areas of medicine. IAM is a really international journal with authors and board members from all around the world. The journal is widely indexed and classified Q1 in category Medicine. 